International Journal of Linguistics, Literature and Translation

ISSN: 2617-0299 (Online); ISSN: 2708-0099 (Print)

DOI: $10.32996 / \mathrm{ijllt}$

Journal Homepage: www.al-kindipublisher.com/index.php/ijllt

IJLLT

\title{
An Analysis of the Intertextuality of Social Media Discourse of Chuka University Students on WhatsApp Platforms
}

\author{
Miriti Gervasio' 8 (D) $\triangle$ Abisaki Oloo Aono ${ }^{2}$ (D), and Nancy Kisala 8 (D), \\ ${ }^{1}$ Lecturer, School of Education and Social Sciences, Turkana University College, Kenya \\ ${ }^{2}$ Tutorial fellow, Department of Teacher Education, School of Education and Social Sciences, Turkana University College, Kenya \\ $\square$ Corresponding Author: Miriti Gervasio, E-mail: miritigervasio80@gmail.com
}

\section{ARTICLE INFORMATION}

Received: June 25, 2021

Accepted: July 27, 2021

Volume: 4

Issue: 7

DOI: $10.32996 /$ ijllt.2021.4.7.22x

\section{KEYWORDS}

Social media discourse, multimodality, intertextuality.

\section{ABSTRACT}

The earliest forms of the internet were developed in the 1960s whereas the first recognizable social media site was created in 1997. Since then, Social media has greatly influenced the way people communicate with one another and continues to gain popularity owing to the technological milestones made in the world of communication. As people communicate via social media interaction platforms, language naturally and inevitably experiences some changes. Therefore, there was a need to undertake a linguistic study to account for such changes and developments in language use. The main concern of this study was to analyze the university students' social media discourse. The discourse analyzed sprung from the WhatsApp interaction platform. The WhatsApp groups utilized were those formed by Chuka University students in Tharaka Nithi County, Kenya. Particularly, the following objective guided the study: to demonstrate the intertextuality nature of social media discourse. The study employed a multimodal semiotic approach as the analytic tool. A descriptive research design and the qualitative technique were employed to analyze data. Both Snowball and purposive sampling procedures were used. Snowballing was used to establish the WhatsApp groups that were used by the students, while the purposive sampling procedure was used to selectively collect texts from WhatsApp groups. The texts that were purposively selected were those that demonstrated the intertextuality nature of social media discourse. The rationale for choosing WhatsApp was the fact that there was a paucity of linguistic studies based on this interaction platform despite its popularity. The study findings revealed that social media discourse exhibits intertextuality in which language is dexterously and creatively used. This study sheds light on language usage and its dynamics. It is hoped that it will enrich knowledge on Multimodality and Semiotic Theory.

\section{Introduction}

Students' texts display aspects of intertextuality owing to the fact that despite students sharing a lot in common, they are part and parcel of the wider society and therefore some features that point to the social, political, and religious life, that happen in the wider society are reflected in their texts. According to Gee (1999), the term social language refers to specific language varieties that are used to establish unique identities and carry out specific activities. A single oral or written text may be in one social language or it can switch between two or more or even mix them. Sometimes, however, a text spoken or written in one variety of language (one social language) may accomplish some sort of switching by incorporating words from another text written or spoken in the same or a different variety of language. This whole process is what is referred to as intertextuality (Gee, 1999).

Similarly, Fairclough (1992) argues that intertextuality is the property of texts whereby one text snatches from other texts and whatever is snatched may be explicitly demarcated or merged into the other, and so the text assimilates, contradicts, or ironically

\section{K C AL-KINDI CENTER \\ $R$ DFOR RESEARCH AND}

Your gateway to world-class research

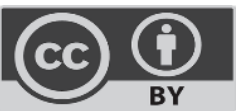

Published by Al-Kindi Center for Research and Development, London, United Kingdom. Copyright (c) the author(s). This open access article is distributed under a Creative Commons Attribution (CC-BY) 4.0 license 
echoes the other and so forth. Zoonen (2017) simply adds that intertextuality is a word that indicates that all texts, whether they are spoken or written, informal or formal, artistic or mundane, are in many ways related to each other. It is a phenomenon that is particularly relevant when one wants to understand the meanings of mass media and online content because more often than not, a particular piece of media content like a crime novel, sports blog, or commercial is related to another media content. This paper aimed at analyzing the texts posted by students on their WhatsApp platform so as to account for intertextuality in their discourses.

\subsection{Objective}

To analyze the intertextuality of social media discourse by Chuka University students on their WhatsApp platforms.

\subsection{Literature Review}

Iqani (2009) carried a study on megatextuality: re-enunciating intertextuality in the age of global media discourse. In analyzing intertextuality in magazines, the study revealed that each individual magazine cover text contains a variety of messages, voices, images, and words which combine in a coherent whole through the use of layout and design techniques, and which then competes with every other magazine cover on the newsstand for the attention of passing consumers. The newsstand is an example of how an intertextual social milieu in the most concrete of terms and, furthermore an example of how a concept of intertextuality can be extended beyond the analysis of texts and into the analysis of social and cultural contexts. This study, on the other hand, was based on the texts written by students on their social media discourse and it revealed that intertextuality is a common phenomenon in such discourses.

Gee (1999) posits that when we actually write or utter a sentence, it has what is often referred to as 'utterance -token meaning' or what he refers to as situated meaning. Situated meanings may come up as a result of particular language forms taking on specific or situated meanings in some specific contexts. The word 'context' in this case is used to refer to an ever-widening set of factors that co-occur with language in use. They include the setting of the material, the people who are present (and what they know and believe), the language used before and after a given utterance, the social relationships of the people who are involved, and their ethnic, gendered, and sexual identities, as well as their institutional and cultural-historical factors.

Ali and Aslan (2016) carried a study on intertextuality as an effective tool in selling products through advertisements. The study revealed that the use of intertextuality by the adverts of agencies purposefully reflects the culture, norms, religion, and allusion in their advertisements to attract their audiences. Similarly, this paper shows how students allude to what happens in the wider society in their day-to-day discourses, as highlighted in the findings. According to Gee (1999), the meaning of an utterance and the context has a lot of interdependence. Certain forms in a language rely on one another so as to be meaningful. These forms are associated with certain types of functions or meanings and this is what is referred to as "meaning potentials".

Iqan's (2009) study that utilized 70 magazines noted that these magazines covered a broad range of genres ranging from women's lifestyle, men's lifestyle, home and garden, sports, gossip, sports, cooking magazines, and more. The texts demonstrated a broad range of differences in both content and form. Each individual magazine has discrete broad and subject matter, aimed at a unique audience, and exists as a text in its own right. However, when considered conceptually from an intertextual perspective and empirically in terms of the messy, overlapping, and plural situation of the newsstand, it becomes clear that the intertextual flows of meaning and signification knit the separate texts into something larger than the sum of their parts.

Fairclough views intertextuality in two dimensions, "manifest and constitutive. Manifest intertextually includes other texts in an explicit way as they can be easily recognized through quotation marks, citations, paraphrasing, and reporting clauses. On the other hand, constitutive intertextuality makes it difficult to uncover the ideological structures hidden in the texts. This type of intertextuality involves the incorporation of other texts hence erecting something new without directly referring to the actual source. Further, Bakhitin (1981) observes that one cannot rely on one text for understanding the entire meaning of the text. This paper analyzes intertextuality in texts written by university students and demonstrates how their discourses cover a myriad of linguistic aspects, as discussed in our findings.

Qayyum (2019) studied intertextually as a catalyst of ideology formation and revealed that most politicians displayed the ideology of nationalism in their discourse by using expressions like the progress of the country, peace and harmony, establishment, and national responsibility. The use of indirect speech enables an author to add and blend his ideas into the actual texts in a manner that is unpredictable. This causes a change of version, which blurs the demarcation hence, the emergence of layers of meanings that forms the basic tenet of intertextuality. This study majored on the students' texts on WhatsApp platforms and revealed that intertextuality is a common phenomenon as evident in our discussion.

\subsection{A Multimodal Social Semiotic Approach}


A multimodal social semiotic approach is concerned with meaning-making in all modes. It is a theoretical approach, which brings all socially organized resources used by people to make meaning into one descriptive and analytical domain. This approach integrates visual communication to the study of discourse analysis by applying it to the social semiotic theory (a theory based upon meaning, social context, and cultural context) to understanding multimodality (Armfield, 2011). This theory is applicable in analyzing the data in this paper since the students' texts exhibit both written and visual communication. The data were therefore analyzed in the light of this theory

\subsection{Methodology}

The study employed a qualitative research technique and descriptive design. Both snowball and purposive sampling procedures were used in obtaining WhatsApp groups in which the texts were extracted. In order to yield the data that the study required, the researcher requested WhatsApp group administrators from the various groups in the university to include them in the WhatsApp groups so as to be in a position to access the texts that were used for analysis. The texts extracted from WhatsApp were analyzed using content analysis.

\subsection{Findings and Discussion}

This paper utilizes a letter and texts that were extracted from the students' social media discourse to shed light on the intertextuality nature of social media discourse. The texts were extracted from students' WhatsApp groups and they explicitly demonstrate how intertextuality is evident in their day-to-day discourses.

Dear Kinuthia and the likes,

You had no right whatsoever to kill Ivy. In case you missed the men's conference of February, we covered this unit extensively. "Sending money to a woman or being in a relationship with her doesn't make you own her!!! It is very very naïve to imagine ati simply coz dame ameingia box yako now her life must revolve around you. A real man should have one girlfriend he truly loves, two side-chicks he sees occasionally, and a secret crush he flirts with. If the beautiful girl he truly loves reciprocates and shows loyalty, gradually eliminate the side chicks and marry her. If the beautiful girl you truly love leaves you for another man or cheats on you, immediately give attention to the 2-side chicks and double your effort on winning the secret crush.

Remember, for every $14 k$ that you send her, there's a more financially stable man who sent 45k last week to 'pay' for her exam. Until you've married a girl, jua mko wengi kwenye kinya'nganiro cha 2022. She has a right to eat all your money, and later decide who she wanna be with or not. Likewise, you have the right to engage multiple girls. If you had been cheating on Ivy... you'd not have felt so angry by rejection. The guilty of cheating buildeth future shock-absorbers in case bae dumbs you with no reason like former sports Cs Echesa was sacked by Uhuru. If Ivy amekuzimia simu respect her space. Don't be petty, insecure, jealous, a psycho, or a nincompoop. Just pick your damn phone and call Carol, muulize mbona siku hizi amenyamaza hivo? Ukiona hajisikii, chokoza Jane muulize utampeleka lunch lini? If Jane ameingia box and unaona mnaenda kejani, text Ivy and tell her "Babe, you may switch off your phone .... but just know I love you to the moon and back. Nalala sasa. ... weka simu "pilot mode" Pepeta Jane kwa ukakamavu na fujo. Let Ivy switch on her phone late at night, apate your message .... ajaribu kukupigia bt uko off. Mtaambiana sorry kesho morning about kuzimiana simu. It becomes a win-win situation for everyone, $n$ no life lost, are we together (િ)હિ.

(Dear Kinuthia and the likes,

You had no right whatsoever to kill Ivy. In case you missed the men's conference of February, we covered this unit extensively. "Sending money to a woman or being in a relationship with her doesn't make you own her!!! It is very very naïve to imagine that simply because a lady has accepted your proposal her life must revolve around you. A real man should have one girlfriend he truly loves, two side-chicks he sees occasionally, and a secret crush he flirts with. If the beautiful girl he truly loves reciprocates and shows loyalty, gradually eliminate the side chicks and marry her. If the beautiful girl you truly love leaves you for another man or cheats on you, immediately give attention to the two side chicks and double your effort on winning the secret crush.

Remember, for every 14 thousand that you send her, there is a more financially stable man who sent 45 thousand the previous week to 'pay' for her exam. Until you have married a girl you should know you are many in the competition like the general election to be held in 2022. She has a right to eat all your money, and later decide whom she wants to be with. Likewise, you have the right to engage multiple girls. If you had been cheating on Ivy... you would not have felt so angry by rejection. The guilty of cheating buildeth future shock-absorbers in case your fiancée dumbs you with no reason like the former sports Cs Echesa was sacked by Uhuru. If Ivy has switched off her phone because of you, respect her space. Do not be petty, insecure, jealous, a psycho, or a nincompoop. Just pick your damn phone and call Carol and ask her why she has not been talking to you, and 
if you realize that she is not willing, call Jane and request her for lunch. If you realize that Jane has accepted your proposal and you heading towards the house, text Ivy and tell her "Babe, you may switch off your phone ..... but just know I love you to the moon and back. I am sleeping now.... Put the phone on flight mode. You do sex with Jane thoroughly. Let Ivy switch on her phone late at night, and then she gets your message ... let her try calling you later but your phone is off. You will apologize to one another the following day about the phone being off. It becomes a win-win situation for everyone, and no life lost, are we in agreement (:):-0).)

\subsection{Introduction}

One can only understand the above text if provided with the context in which it occurred. The writer presupposes that all the readers are aware of what happened between a university student named lvy, who was allegedly killed by her fiancée after she rejected him. The writer tries to disapprove of the action taken by Kinuthia. The writer however gives a strange solution to anyone who finds himself in the scenario that Kinuthia found himself in. Through this text, this study attempted to explore the possibility of a text to exhibit a myriad of linguistic aspects that are unique to university students. It also explores the current issues lightly affecting the nation as discussed below.

\subsection{Allusion and Presupposition}

In the text, there is the allusion of Ivy, Kinuthia, Carol, and Jane. Ivy represents a girl that one loves while Kinuthia stands for a man who is in a situation that Kinuthia was. There is also a presupposition of the men's conference, which according to the social media context took place from $14^{\text {th }}$. February to $16^{\text {th }}$, February whereby men came up with a few resolutions on how to deal with their lovers. One of the resolutions was to deter themselves from battering or killing their lovers. The writer of this text assumes that everyone is aware of those resolutions and he argues that he covered the unit extensively. It was a three-day-long imaginary conference that was designed to avoid valentine celebrations where men would get time to talk about all kinds of things that affect them. Boyfriends and husbands had to optimize the opportunity provided by the men's conference to avoid doing all those romantic things for their partners and wives. Men everywhere fear Valentine's Day because of the demands and pressures that come with it. This is because men feel that the responsibility to make the day special has been left only on their shoulders.

The event was so well choreographed that even a programme was availed complete with a master of ceremony (MC), key speakers, and agenda for the entire three days. It is not easy to connect and get the interpretation of this message without prior knowledge of what the men's conference was all about. This demonstrates the intertextuality of social media messages. Secondly, one has to be aware of the story of Ivy and Kinuthia so as to make out the meaning of the letter written to Kinuthia. One needs to know the circumstances that led to the death of Ivy. The writer of the letter also uses imagery to liken a man who has been dumped (rejected) by his girlfriend without any good reason to the cabinet secretary (CS) Echesa who was sacked by the Kenyan president Uhuru Kenyatta. This also shows the intertextuality of the social media message. This confirms what Zoonen (2017) says about intertextuality; that all texts be they formal or informal, written or spoken, artistic or mundane; are related to each other and that this feature is relevant in understanding the meaning of online content and mass media.

\subsection{Linguistic and Paralinguistic Features}

The above 'letter' has a myriad of aspects of language. I will give an account of some of the peculiar linguistic features. As far as morphological and phonological processes are concerned, it is evident that compound words such as 'side-check' and 'secret crush' have been formed through a morphological process called compounding. The word 'psycho' has been formed through a process called clipping from the word psychotic. An abbreviation is realized through the word 'CS' (Cabinet Secretary). Clipping as a morphological process is also evident in the word " $\mathrm{COz}^{\prime \prime}$ (because). Phonological features are evident through the process of elision where a word like 'but' is written as "bt" and also the word 'because' written as "coz" and 'and' as ' $n$ '.

Paralinguistic features are represented by the use of an emoji. The smiling emoticon is used at the end of the letter. At the same time, there are repeated punctuation marks where we have repeated exclamation marks and full stops in several instances. They are meant to emphasize the message being put across while logographic features are evident in the usage of Arabic numbers like "2" to stand for two and ' $\mathrm{k}$ ' to stand for a thousand.

\subsection{Informality}

The letter (text) is quite informal considering the tone and several other factors that point to the informal usage of language. There is contraction as seen in the words 'doesn't', 'you'd', and 'you've'. There are several instances where we have imperative sentences like 'Remember, for every 14k that you send her, there's a more financially stable man who sent 45k last week to 'pay' for her exam', this is a pointer to verbalization that shows informality. The active voice is used as opposed to the passive one. The usage of slang 
and colloquial forms of the words underscores the high level of informality. Consider the usage of words such as 'dame', 'flirts', 'secret crush', 'damn', 'dumb', 'box' and the Kiswahili words "pepeta" (to have sex) 'fujo' (force). The use of sheng is evident for instance, where we have "kejani" (in the house). The informal use of the language, use of colloquial forms, and Sheng shows how students mark their identities in their interactions

\subsection{Code-switching}

Code-switching is evident in the text as the writer comfortably mixes three linguistic codes. English is the one that dominates followed by Kiswahili and then 'sheng'. The use of the three linguistic codes shows students' competence in the three codes. One of the main reasons for code-switching is to enable one to express himself or herself with ease. Some words are better said in a certain language than the other. Consider the phrase "pepeta Jane kwa ukakamavu na fujo" if the same is said in English the effect would not be the same.

\subsection{Creativity}

Creativity in social media is demonstrated by the way the writer is able to do comparisons, his/her ability to make a better choice of words, the ability to exhibit intertextuality in the text as well as the use of some stylistic devices with a lot of ease. Consider the phrase "babe you may switch off your phone ... but just know I love you to the moon and back...." The statement is not only ironical but also metaphorical and hyperbolic. Ironically, he would tell his 'Ivy' that he loves her so much when he is warming up for Jane. By telling Ivy that he loves her to the moon and back is metaphorical and is also an overstatement. The writer also uses onomatopoeia in the use of the word "pepeta" which in the context of the text means to engage in sex. The writer also metaphorically compares winning a girl in a situation that has a lot of competition just like winning a seat in the election ".... jua mko wengi kwenye kinyanganiro cha 2022". The writer is talking about the 2022 election that will be held in Kenya. This is just a presupposition that the reader is supposed to be aware of. The choice of the word 'pilot mode' is derived from the word airplane/ flight mode which is an option in the phone that when switched on, one cannot be reached over the phone. The whole text is laced with humor as the writer attempts to justify why a man should have multiple girlfriends particularly where he/she paradoxically states that, the guilty of cheating buildeth the future shock-observers'.

\subsection{Discourse Features}

Discourse features are also evident where the writer begins with a salutation and then progressively and logically drives his point home. The reason for writing the letter was to show that Kinuthia had no reason to kill lvy. Although the letter lacks the address and the closing tag, the writer addresses Kinuthia directly. Coherence and cohesion are indicated by the use of the connectors such as 'likewise', 'until', and 'if '. The language is used informally just because the letter is informal.

\subsection{Semantic features}

Turning on the semantic aspect, it is explicit that some words and expressions can only be understood from the context. The inferences can only be made from the context in that compound words like "side-chick" and "secret crush" are only understood from the social point of view hence, social meaning. Side-check is a lady that a man has besides his girlfriend or wife while a secret crush, on the other hand, is that girl or lady that one admires and 'hangs' out with but because of the circumstances prevailing in their relationship, they are not expected to have any sexual relationship. Like in the case of the letter written to Kinuthia, Carol, and Jane are the side chicks while Ivy is the 'legal' or the official girlfriend.

Affective meaning is evident when the writer refers to "Ivy' as "bae" or "babe". The word "bae" and "babe" comes from the word baby. The word baby conceptually means a small child. However, in the context of this letter, it refers to a person of the opposite sex that one is so intimate with. Another fascinating example of affective meaning in this letter is the use of the word box.... "Kama Jane ameingia box" (if Jane has accepted the proposal) conceptually, the word 'box' has a meaning that is obvious but the social and the affective meaning comes into play and the word acquires another meaning, that is a girl accepting the proposal made by a boy. If one interprets the sentence literally, it would mean that.... "if Jane has entered in the box" which is meaningless just like interpreting the clause "pepeta Jane kwa ukakamavu na fujo". It is therefore explicit that context plays an integral role in decoding the social media messages and that intertextuality is common in students' social media messages.

\subsection{Semantic and Language -Context Analysis Features}

Semantics studies the meanings that can be expressed convincingly and it is claimed to be a component discipline of linguistics that is the most fruitful and exciting point of departure. Semantics is core in the study of the human mind-thought processes, conceptualization, and cognition. Several words acquire different meanings depending on the context where they are applied (Leech, 1974). The social context plays an integral role in determining what a certain linguistic form or expression means. 
This study confirms that some meanings of words and phrases as used in the social media discourse of university students could only be interpreted depending on the context in which such words were used. In the social media context, some words are associated with some peculiar meaning that can be interpreted only when a person is conversant with what is happening in the wider society. A good example is the word "nyerified" and "femicide". The former is derived from the word Nyeri while the latter is from the word female. Nyeri is a community in Kenya that is stereotyped with females battering or killing their husbands and therefore if a person tells another that he will be "nyerified", then it implies that such an inhuman act may be perpetrated to them. Without the social context, one may not understand the meaning of this coined word. Similarly, "femicide" was coined after several instances were reported of male students killing their female lovers. This word is formed by clipping the word female and adding a morpheme -"cide" which is associated with killing as seen in words such as insecticide, suicide, herbicide, homicide, and so on. Consider the following example;

A: Men have got physical strength and cannot be threatened by your threats (Men are physically strong; therefore, cannot be threatened by your threats) $B$ : Ben, ety physical strength,", not ol men are strong ", give it time en women are going to react to it too. $U$ guys are going to be nyerified,", and killed too coz we have other skills hatutakaa hapo ety juu mko na nguvu mtunyanyase.

(Ben, so, you are talking of physical strength, , not all men are strong ${ }_{\prime \prime \prime}$ give it time and women are going to react to it too. you guys are going to be nyerified ${ }_{m}$, and killed too because we have other skills, we will not stay there you exploit us because you have physical strength)

C: Okay, as we end femicide, what is your take on that murder by MISS PRISONS? Y were you feminist against the court orders towards her? I wish huyu boy is sentenced to death najua mtasema mpewe mumuwe.

(Okay, as we end femicide, what is your take on that murder by MISS PRISONS? Why were you feminist against the court orders towards her? I wish this young man is sentenced to death. I know you will say that he be given to you so that you kill him.)

As already discussed, the words, "femicide" and "nyerified" have been used in the example above and for one to understand their meaning, the social context is required hence situated meaning as Gee (1999) posits. Similarly, the word "nyerification" was also coined and has a similar meaning with "nyerified". This kind of coinage has a bearing on the social life of people outside the social media, their perceptions and attitudes towards other people and, their ethnicity and gender, which is a pointer to the intertextuality of the students' social media discourse.

Other examples of coinage include words like "minji minji" and "ndengu ndengu" which originated from Kirinyaga County during the 2017 elections to refer to the main candidates for the gubernatorial seat. Denotatively, "minji" means 'green peas' while "ndengu" means 'green grams' while connotatively, the former stands for the type of girls that are cool, soft, and attractive while the latter stands for the rough and unattractive type. Initially, the reduplicated, "minji minji" referred to Ann Waiguru, one of the candidates while "ndengu ndengu" referred to Martha Karua (the other candidate) before they were generalized in social media to mean the Waiguru type and the Karua type respectively. Closely related to these words is "yellow yellow" which literally means a type of color but in the social context, the form refers to those 'very attractive light-skinned girls whose complexion resembles some ripe fruit such as bananas, mangoes, or oranges. Perhaps the word has got some relationship with the Kiswahili word" iva" (ripe). If a person says for instance "Jane ameiva sana" it means that 'Jane looks beautiful' but in another context, if a person is going to do an exam and he/she says "ameiva" it means that he/ she is prepared for the exam. One can therefore draw some relationship between "yellow yellow" and the Kiswahili word "iva" which means 'ripe'

Semantically speaking, some words have acquired new meanings in the social media discourse. This study found that there are a number of words that have either been borrowed or coined and then used differently from their initial meaning. For instance, there are words that generally refer to the relationship that exists among the males and females and are used in a peculiar manner. The word "baby" means a small child (literally). However, the word has acquired a new meaning and has several forms that have emerged over time. The word is currently used to refer to adults who are in an intimate relationship. From the word baby, through the dynamics of language, we have other generics of the word that include: "bae", "baib", "beb", "babe", "baibe", "baz", and "bbie". The most common nowadays is "bae".

The other word that is metaphorically used is "sweetheart" to refer to people of the opposite sex that are in a close relationship. The word has acquired several other forms that include: "sweat@"," "swee", "swi", "sweathat", "switie", "swrht",swiri and "swr" 
On the other hand, the word "ancestor" is used cognitively, to mean people who died a long time ago. In social media, the word means an old man who has a sexual relationship with a young man. Similarly, the word "fossil" means the mineralized remains of an animal or plant or anything that is extremely old, extinct or outdated but the same form acquires a social meaning, that is, it refers to an old man having an affair with a young woman.

Several words have emerged to describe young women having affairs with old men. The first one is 'slay queen' that is' a compound noun that is formed from a verb and a noun. To slay means to kill. It, therefore, implies that a slay queen, is a queen who has the potential of "killing". The killing here is not literal, rather the sense implies that a slay queen has traits such as being inhuman especially when it comes to the financial aspect of the 'sponsor' or 'blessor'. A point in case is the alleged relationship between one of the Kenyan Governors (Obado) who in this case can be considered to be the sponsor while Sharon, the slay queen. It is alleged that the slay queen was demanding so much from him hence the aspect of being inhuman comes in. These words are not only used in social media but also in the wider society meaning that students do not live exclusively in isolation but interact with others. This demonstrates the intertextuality aspects in students' social media discourse.

\section{0 Conclusion}

The objective of this paper was to analyze the intertextuality of social media discourse by Chuka University students. The findings revealed that $i$ is a linguistic phenomenon that is evident in students' social media discourse just like it is common in other genres. This aspect is demonstrated by the fact that students' interactions are characterized by words and phrases that are used by the wider society because they are part and parcel of the same society and they do not live in isolation. Similarly, the issues addressed in their interactions allude to what is happening in the wider society. Such issues are religious, socioeconomic, and political in nature. This paper also established that students use language dexterously and creatively. There is a lot of presupposition, allusion, use of discourse features. The language is used informally and code-switching is a common phenomenon.

\section{References}

[1] Ali, A \& Aslam, A (2016). Intertextuality: an effective tool in selling products through advertisements. PUTAJ- Humanitie and Social Sciences 23 (2) $141-150$

[2] Armfield, D, (2011) Multimodality: A social semiotic approach to contemporary communication. Gunther Kress, Technical Quarterly, 20:3 347-349).

[3] Bakhtin, M (1981). The dialogic Imagination (Trans, Caryl Emersion, Michael Haloquist, and edit Michael Haloquest). The University of Texas Press: USA

[4] Fairclough, N. (1992). Discourse and society Disco and text: Linguistic and intertextual analysis within discourse analysis. Retrieved from https://doi.org/10.1177/0957926592003002004 retrieved on 15 April 2019

[5] Gee, L. P. (1999). An introduction to discourse analysis; theory and method. London and Newyork: Routeledge.

[6] Iqan, M (2009). Mgatextuality: Re-enciating media intertextuality in the age of global discourse. Media@LSEelectronic Working Papers: London

[7] Leech, G. (1974) semantics, London: Penguin pp. Xii +386 ( $2^{\text {nd }}$ edition entitled Semantics the study of meaning)

[8] Qayyun, N. (2019). Intertextuality as a catalyst for ideology formation. A study of media discourse dynamics. International journal of English Linguistics 9 (3) 249-259

[9] Zoonen, W (2017) paradoxical implications of persocial media use for work. New technology work and employment 32 (3) retrieved from https://doi.org/10.111/ntae.12098-retrieved on 20th May 2019 